\title{
ANALISIS PENDAPATAN USAHATANI TOMAT DI DESA TONSEWER KECAMATAN TOMPASO KABUPATEN MINAHASA
}

\author{
C. Talumingan \\ Rine Kaunang \\ Ridwan Habaludin
}

\begin{abstract}
This study aims to determine the costs and farm income. Research carried on in March to May 2010 in the village of Tonsewer, district of Tompaso, Regency of Minahasa.

The data obtained in this study include primary data and secondary data. The method of collecting data was obtained by interview using the questionnaire as a tool in data collection. Primary data were obtained from tomato farmers and secondary data obtained from the relevant authorities of this research.

Results showed that most farmers in the village of respondents aged 28-67 years, having elementary through high school levels, the number of dependents a family of 3 to 4 people and is the owner of tenant farmers.

This study uses the income analysis to determine the level of income from tomato farmers and comparative analysis between revenue and costs to determine the level of success of farming tomatoes.

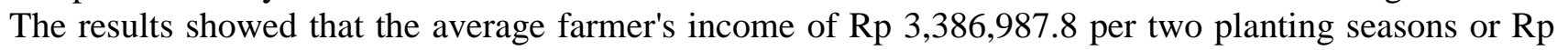
$4,908,784.6$ per one planting season. $\mathrm{R} / \mathrm{C}>1$ is a successful farmer in tomato farming.
\end{abstract}

Keywords: Tomato Farming, Revenue

\section{PENDAHULUAN}

\section{Latar Belakang}

Peranan sektor pertanian sangat penting bagi bangsa Indonesia karena sektor ini mampu menyediakan lapangan pekerjaan, memasok pangan dan menyumbangkan devisa. Indonesia mempunyai potensi dan memberikan prospek yang baik dalam mengembangkan sektor pertanian di karenakan Negara kita adalah Negara agraris yang sebagian besar penduduknya bergelut dalam usahatani ( Soekartawi, 1995).

Untuk itu, pemerintah bersama masyarakat harus berperan aktif dalam memajukan usahatani dalam rangka peningkatan perekonomian Negara, peningkatan taraf hidup dan kesejateraan seluruh rakyat Indonesia.

Besarnya pendapatan yang di terima petani melalui kegiatan usahataninya banyak di tentukan oleh perilaku petani itu sendiri dalam hal jenis cabang usahatani serta mempengaruhi faktorfaktor produksi seefektif dan seefisien mungkin.
Selain itu pula, pendapatan petani secara tidak langsung di pengaruhi oleh keadaan iklim , namun juga oleh harga produk yang bersangkutan. Peningkatan pendapatan di sektor pertanian perlu mendapat perhatian di sebabkan karena pada umumnya penduduk Indonesia hidup dan di hidupkan dari usaha pertanian (Ronny, 2010).

Tanaman hortikultura mempunyai kedudukan yang sangat penting dalam kehidupan masyarakat maupun perekonomian Negara. Dalam kehidupan masyarakat, peranannya sebagai sumber gizi. Sedangkan dalam perekonomian mempunyai nilai ekonomis yang tinggi di lihat dari sumberdaya terhadap peningkatan Devisa Negara (Patricia, 2001).

Komoditas Horitikultura merupakan komoditas yang dikonsumsi setiap hari, sehingga perlu untuk dikembangkan. Perlu dikembangkannya komoditas-komoditas Hortikultura karena komoditas ini memiliki nilai Ekonomis yang tinggi seperti halnya pada tomat. 
Tomat dapat dikonsumsi dalam bentuk Sambal Tomat dan Jus Tomat. Melihat nilai Ekonomis dari Tomat, maka apabila dikembangkan dalam suatu sistem usahatani yang komersial dapat meningkatkan pendapatan petani.

Tomat (Lycopersicum esculetum) merupakan salah satu komoditas hortikultura dari kelompok jenis sayuran buah tahunan yang dapat di tanam ditanah dataran rendah atau dataran tinggi. Buah ini merupakan sumber vitamin A dan C (Patricia, 2001).

Di Sulawesi Utara, khususnya di Desa Tonsewer kecamatan Tompaso merupakan salah satu daerah penghasil tomat, dimana sebagian besar $(90 \%)$ penduduk yang ada di dese tersebut berprofesi sebagai petani Tomat.

Seorang petani yang mengusahakan tanah pertaniannya dengan berwawasan bisnis berarti mereka mengusahakan uasahataninya secara komersial. Dari cara berusahatani sudah tentu petani tersebut ingin mendapatkan hasil yang optimum dan juga pendapatan yang setinggitingginya tentunya dengan memperhatikan efisiensi penggunaan faktor-faktor produksi.

\section{Perumusan Masalah}

Berdasarkan uraian latar belakang di atas yang menjadi masalah dalam penelitian ini adalah berapa besar biaya yang di keluarkan petani dan berapa besar pendapatan yang akan di terima petani dari usahatani tomat yang di kelolahnya.

\section{Tujuan dan Manfaat Penelitian}

Penelitian ini bertujuan untuk mengetahui besarnya biaya dan pendapatan usahatani tomat. Penelitian ini di harapkan bisa memberi manfaat bagi petani tomat mengenai tingkat pendapatan dari usahatani yang di kelolahnya, dan kiranya dapat memberi manfaat berupa informasi bagi petani dan pihak-pihak terkait yang memerlukannya.

\section{METODE PENELITIAN}

\section{Metode Pengumpulan Data}

Data yang di peroleh dalam penelitian ini meliputi data primer dan data sekunder. Metode pengumpulan data di peroleh dengan teknik wawancara yang menggunakan daftar pertanyaan sebagai alat bantu dalam pengumpulan data. Data primer di peroleh dari petani tomat, untuk data sekunder di peroleh dari instansi-instansi yang terkait dengan penelitian ini.

\section{Metode Pengambilan Sampel}

Metode pengambilan sampel dalam penelitian ini adalah metode purposive samplin, dengan jumlah petani yang akan di teliti sebanyak 20 sampel.

\section{Konsep Pengukuran Fariabel \\ Besarnya biaya produksi}

Biaya produksi yaitu biaya yang di keluarkan petani dalam satu kali proses produksi, yang meliputi biaya Tatap dan biaya variabel. Biaya tetap ada biaya yang tidak berhubungan lansung dengan barang yang di produksi yangg terdiri dari pajak dan penyusutan alat.

Biaya variabel yang dimaksud yaitu biaya langsung yang mempengaruhi besarnya produksi yang di hasilkan petani selama satu kali produksi, Yang terdiri dari:
- Bibit (Rp)
- Pupuk (Rp)
- Pestisida (Rp/liter)
- Kas (Rp)
- Transport (Rp)
- Tenaga kerja (Hok)

\section{Besarnya pendapatan}

Pendapatan yaitu selisih antara total penerimaan dan total pengeluaran dalam suatu usahatani.

\section{Variabel penunjang}

- Luas lahan yaitu lahan yang di tanam tomat yang di nyatakan dalam hektar.

- Jumlah produksi yaitu di peroleh dalam satu kali proses produksi dan dua kali proses produksi yang di nyatakan dalam kilogram.

- Harga yaitu harga yang berlaku di tingkat petani yang di gunakan dalam $(\mathrm{Rp} / \mathrm{Kg})$

- Karakteristik petani:

○ Jumlah anggota keluarga (orang)

- Umur ( Tahun )

○ Tingkat pendidikan

\section{Analisis Data}

Analisa data yang di gunakan dalam penelitian ini adalah deskriptif. Untuk mengetahui 
tingkat pendapatan usahatani tomat di gunakan analisa pendapatan menurut Soekartawi (1995):

$$
\mathrm{Pd}=\mathrm{TR}-\mathrm{TC}
$$

Di mana:

$\mathrm{Pd}=$ Pendapatan Usahatani

$\mathrm{TR}=$ Total Revenue $($ Total Penerimaan $)$

$\mathrm{TC}=$ total Cost (Total Biaya)

Untuk mengetahui analisis perbandingan antara penerimaan dan biaya, dapat di lihat dengan rumus sebagai berikut:

$$
\mathrm{a}=\mathrm{R} / \mathrm{C}
$$

Di mana:

$\mathrm{a}=$ Indeks Pendapatan

$\mathrm{R}=$ Penerimaan

$\mathrm{C}=$ Biaya

Apabila:

$\mathrm{R} / \mathrm{C}=1$ usahatani tidak untung dan tidak rugi (seimbang)

$\mathrm{R} / \mathrm{C}<1$ usahatani mengalami kerugian

$\mathrm{R} / \mathrm{C}>1$ usahatani menguntungkan

\section{Waktu Dan Tempat Penelitian}

Penelitian ini di lakukan selama tiga bulan dari bulan maret sampai bulan mei 2010. Lokasi penelitian yaitu Desa Tonsewer Kecamatan Tompaso Kabupaten Minahasa.

\section{HASIL PENELITIAN DAN PEMBAHASAN}

\section{Umur}

\section{Keadaan Umum Petani Sampel}

Umur petani akan mempengaruhi produktivitas kerja atau peranannya dalam pengambilan keputusan dari berbagai alternatif pekerjaan yang di lakukan. Umur petani memiliki hubungan dengan kemampuan petani dalam bekerja. Jika di tinjau dari segi fisik, semakin tua umur seorang setelah melewati batas umur tertentu, maka semakin berkurang kemampuan untuk bekerja. Umur petani responden menurut hasil penelitian dapat di lihat dalam Tabel 1 .

Dari Tabel 1 dapat di lihat bahwa kelompok umur 28 sampai 37 sebanyak 5 orang petani atau 33.33 persen dari total petani responden. Untuk kelompok umur 38 sampai 47 tahun sebanyak 5 orang petani atau 33.33 persen, untuk kelompok
Tabel 1. Jumlah Responden Berdasarkan Kelompok Umur

\begin{tabular}{|l|c|c|}
\hline $\begin{array}{c}\text { Umur Petani } \\
\text { (Tahun) }\end{array}$ & $\begin{array}{c}\text { Jumlah } \\
\text { Petani } \\
\text { (Orang) }\end{array}$ & $\begin{array}{c}\text { Persentase } \\
(\%)\end{array}$ \\
\hline $28-37$ & 5 & 33.33 \\
\hline $38-47$ & 5 & 33.33 \\
\hline $48-57$ & 4 & 26.67 \\
\hline$\geq 58$ & 1 & 6.67 \\
\hline Total & 15 & 100 \\
\hline
\end{tabular}

Sumber : Diolah dari data primer 2010

48 sampai 57 tahun sebanyak 4 orang atau 26,67 persen, dan untuk kelompok umur $\geq 56$ tahun sebanyak 1 orang atau 6.67 persen dari total responden.

\section{Tingkat Pendidikan}

Pendidikan merupakan salah satu faktor penting dalam usaha peningkatan kualitas sumberdaya manusia, serta peningkatan kualitas intelektual dan wawasan seseorang. Bagi petani pendidikan yang di peroleh dapat di aplikasikan dalam usahatani yang di kelolah. Berdasarkan hasil penelitian, tingkat pendidikan petani responden bervariasi mulai dari tingkat Sekolah Dasar (SD) sampai sekolah menangah atas (SMA) dapat di lihat pada Tabel 2.

Tabel 2. Tingkat Pendidikan Dan Persentasi Petani Responden di Desa Tonsewer

\begin{tabular}{|l|c|c|}
\hline $\begin{array}{c}\text { Tingkat } \\
\text { Pendidikan }\end{array}$ & $\begin{array}{c}\text { Jumlah } \\
\text { Petani } \\
\text { (orang) }\end{array}$ & $\begin{array}{c}\text { Persentasi } \\
(\%)\end{array}$ \\
\hline SD & 5 & 33.33 \\
\hline SMP & 3 & 20 \\
\hline SMA & 7 & 46.67 \\
\hline Total & 15 & 100 \\
\hline
\end{tabular}

Sumber : Diolah dari data primer 2010

Tabel 2 menunjukan bahwa dari 15 orang responden petani tomat, tingkat pendidikan responden paling banyak berada pada tingkat sma yaitu sebanyak 7 orang responden atau 46.67 persen, sedangkan untuk responden petani yang berpendidikan SMP sebanyak 3 orang atau 20 persen, dan yang berpendidikan SD sebanyak 5 orang atau 33.33 persen. Hal ini menunjukan adanya kesadaran masyarakat akan pentingnya pendidikan. 


\section{Jumlah Tanggungan}

Hasrat petani untuk mencapai taraf kehidupan yang lebih baik bagi keluarga, dalam banyak hal merupakan dorongan yang efektif untuk mempertinggi hasil usahatani (Mosher, 1991).

Keluarga merupakan unit masyarakat terkecil dan biasanya terdiri dari beberapa orang yaitu ayah, ibu, dan anak-anak. Jumlah anggota keluarga merupakan salah satu faktor penunjang keberhasilan dalam berusahatani. Di bawa ini dapat di lihat jumlah tanggungan keluarga dari petani tomat di Desa Tonsewer.

Tabel 3. Jumlah Tanggungan Keluarga Petani Responden di Desa Tonsewer

\begin{tabular}{|l|c|c|}
\hline $\begin{array}{c}\text { Jumlah } \\
\text { Tanggungan } \\
\text { (orang) }\end{array}$ & $\begin{array}{c}\text { Jumlah Petani } \\
\text { (orang) }\end{array}$ & $\begin{array}{c}\text { Persentase } \\
(\%)\end{array}$ \\
\hline$\leq 2$ & 2 & 13.33 \\
\hline $3-4$ & 10 & 66.67 \\
\hline$\geq 5$ & 3 & 20 \\
\hline Total & 15 & 100 \\
\hline
\end{tabular}

Sumber : Diolah dari data primer 2010

Dari tabel di atas, dapat dilihat bahwa dari 15 orang responden petani ada 2 responden petani atau 13.33 persen memiliki jumlah tanggungan $\leq$ 2, 10 responden petani atau 66.67 persen memiliki jumlah tanggungan 3 sampai 4 orang, dan 3 responden petani atau 20 persen memiliki jumlah tanggungan $\geq 5$. Umumnya jumlah anggota keluarga yang terhitung dalam jumlah tanggungan ini membantu dalam hal penyediaan tenaga kerja. Dengan demikian ketersediaan tenaga kerja dalam keluarga akan mempengaruhi penyerapan tenaga kerja dari luar keluarga. Akan tetapi, di lain pihak makin banyak jumlah anggota keluarga makin besar pula biaya yang di perlukan untuk memenuhi kebutuhan hidup keluarga.

\section{Luas Lahan}

Luas lahan yang di olah petani sangat menentukan besar kecilnya hasil produksi . luas lahan responden berkisar antara 0.15 hektar sampai 0.35 hektar.

Tabel 4, menunjukan bahwa luas lahan yang paling banyak di miliki petani responden adalah $0.16-0.20$ hektar dengan jumlah responden 9 orang dengan jumlah persentase 60 , untuk luas
Tabel 4. Persentase dan Luas Lahan Petani Responden di Desa Tonsewer

\begin{tabular}{|l|c|c|}
\hline $\begin{array}{c}\text { Luas Lahan } \\
\text { (ha) }\end{array}$ & $\begin{array}{c}\text { Jumlah } \\
\text { Responden }\end{array}$ & Persentase \\
\hline $0-0.15$ & 2 & 13.33 \\
\hline $0.16-0.20$ & 9 & 60 \\
\hline $0.21-0.25$ & 1 & 6.67 \\
\hline$\leq 0.26$ & 3 & 20 \\
\hline Total & 15 & 100 \\
\hline
\end{tabular}

Sumber : Diolah dari data primer 2010

lahan $\geq 0.26$ hektar dengan jumlah responden 3 orang dengan persentase 20.Luas lahan $0-0.15$ hektar dengan jumlah responden 2 orang dengan persentase 13.33 dan untuk luas lahan $0.21-0.25$ dengan jumlah responden 1 orang dengan persentase 6.67 .

\section{Biaya Produksi}

Pengeluaran atau biaya produksi adalah keseluruhan biaya yang di gunakan dalam satu proses produksi yang berlangsung dalam satu tahun. Biaya produksi terdiri dari biaya tetap dan biaya variable. Pada usahatani tomat di Desa Tonsewer, biaya tetap adalah biaya pajak, sedangkan biaya variable meliputi biaya pestisida, tenaga kerja dan angkut.untuk lebih jelas mengenai biaya produksi ini dapat di lihat pada Tabel 5. Dari Tabel 5. Dapat di lihat bahwa ratarata biaya terbesar adalah biaya yang di keluarkan untuk tenaga kerja Rp. 1.000 .000 dengan persentase 20.75, biaya pupuk Rp. 647.222 dengan persentase 13.42 , biaya pestisida $\mathrm{Rp}$. 578.833.33 dengan persentase 12.01, biaya angkutan Rp. 397.333.33. untuk biaya rata-rata penggunaan benih Rp. 157.833.33 dengan persentase 3.28 , biaya rata-rata penusutan alat $\mathrm{Rp}$. 13.282.07 dengan persentase 0.28 dan rata-rata biaya pajak tanah yaitu 21.000 dengan persentase 0.43 .

Dari Tabel 5 dapat di lihat juga untuk penggunaan benih dalam 1 kali musim tanam dan 2 kali musim tanam berbeda rata-rata pengeluaranya, karna harga benih yang berfluktuasi. Penggunaan pestisida dalam 1 kali musim tanam dan 2 kali musim tanam berbeda rata-rata pengeluarannya, di karenakan pada harga pestisida yang berfariasi dan penggunaan pestisida yang berbeda-beda pada 
Tabel 5. Jumlah Rata-Rata dan Persentase Biaya produksi perhektar Usahatani Tomat

\begin{tabular}{|c|c|c|c|}
\hline Komponen Biaya & $\begin{array}{l}\text { Rata-Rata } \\
\text { (Rp) }\end{array}$ & $\begin{array}{c}\text { Persentase } \\
(\%)\end{array}$ & $\begin{array}{c}\text { Jumlah } \\
\text { Responden }\end{array}$ \\
\hline \multicolumn{4}{|l|}{ Biaya Tetap } \\
\hline \multicolumn{4}{|l|}{ - Pajak } \\
\hline a. X1 (untuk 1 kali musim tanam) & 21.000 & 0.43 & 9 \\
\hline b. X2 (untuk 2 kali musim tanam) & 15.000 & 0.31 & 6 \\
\hline \multicolumn{4}{|l|}{ - Penyusutan Alat } \\
\hline a. X1 (untuk 1 kali musim tanam) & 13.282 .07 & 0.28 & 9 \\
\hline b. X2 (untuk 2 kali musim tanam) & 10.178 .56 & 0.21 & 6 \\
\hline \multicolumn{4}{|l|}{ Biaya Variabel } \\
\hline \multicolumn{4}{|l|}{ - Biaya Benih } \\
\hline a. X1 ( untuk 1 kali musim tanam ) & 157.833 .33 & 3.28 & 9 \\
\hline b. X2 ( untuk 2 kali musim tanam ) & 149.166 .66 & 3.10 & 6 \\
\hline \multicolumn{4}{|l|}{ - $\quad$ Biaya Pestisida } \\
\hline a. X1 (untuk 1 kali masa tanam ) & 283.611 .11 & 5.89 & 9 \\
\hline b. X2 ( untuk 2 kali masa tanam ) & 578.833 .33 & 12.01 & 6 \\
\hline \multicolumn{4}{|l|}{ - Biaya Pupuk } \\
\hline a. X1 ( untuk 1 kali masa tanam ) & 647.222 & 13.42 & 9 \\
\hline b. X2 ( untuk 2 kali masa tanam ) & 462.500 & 9.60 & 6 \\
\hline \multicolumn{4}{|l|}{ - Biaya Tenaga Kerja } \\
\hline a. X1 ( untuk 1 kali musim tanam) & 869.444 .44 & 18.04 & 9 \\
\hline b. X2 ( untuk 2 kali musim tanam) & 1.000 .000 & 20.75 & 6 \\
\hline \multicolumn{4}{|l|}{ - Biaya Angkutan } \\
\hline a. X1 ( untuk 1 kali musim tanam) & 213.888 .88 & 4.43 & 9 \\
\hline b. X2 ( untuk 2 kali musim tanam) & 397.333 .33 & 8.25 & 6 \\
\hline Jumlah & 4.819 .293 .71 & 100 & \\
\hline
\end{tabular}

Sumber : Diolah dari data primer 2010

saat pengolahan usahatani tomat. Penggunaan pupuk sangat mempengaruhi dalam peningkatan produksi, dengan luas lahan yang berfariasi dan tingkat kesuburan tanah yang berbeda-beda maka untuk rata-rata penggunaan pupuk dalam satu kali musim tanam dan 2 kali musim tanam berbeda. Begitu juga penggunaan tenaga kerja yang di gunakan dalam 1 kali musim tanam dan 2 kali musim tanam berbeda rata-rata pengeluarannya. Untuk biaya angkuta produksi rata-rata pengeluarannya berbeda karena hasil produksi usahatani yang berbeda-beda pada saat musim panan tiba.

\section{Biaya Pajak}

Biaya Pajak yaitu pajak tanah yang di bayar per Tahun. Dalam hal ini biaya produksi di hitung per satu musim tanam. Menurut hasil penelitian, biaya pajak di tanggung oleh pemilik lahan untuk status milik sendiri yaitu sebanyak 15 petani. Pajak merupakan salah satu unsur biaya yang perlu di perhitungkan petani. Pajak yang di masukan kedalam biaya tetap adalah pajak tanah.

Penyusutan merupakan penurunan nilai suatu yang disebabkan oleh bertambahnya umur, alat, adanya keausan, kerusakan atau pengurangan yang ditentukan. Penyusutan peralatan berjalan terus menerus, mulai dari soal dibeli sampai akhir umur ekonomisnya.

Pajak dan penyusutan marupakan salah satu unsur biaya yang perlu di perhitungkan petani. 
Tabel 6. Rata-Rata Biaya Pajak dan Penyusutan

\begin{tabular}{|c|c|c|}
\hline Komponen Biaya & $\begin{array}{l}\text { Rata-Rata } \\
\quad(\mathrm{Rp})\end{array}$ & $\begin{array}{l}\text { Persen- } \\
\text { tase } \\
(\%)\end{array}$ \\
\hline \multicolumn{3}{|l|}{ Pajak } \\
\hline $\begin{array}{ll}\text { a. } & \text { X1 (untuk 1 kali } \\
\text { musim tanam) }\end{array}$ & 21.000 & 35.32 \\
\hline $\begin{array}{l}\text { b. } \begin{array}{l}\text { X2 (untuk } 2 \text { kali } \\
\text { musim tanam) }\end{array} \\
\end{array}$ & 15.000 & 25.23 \\
\hline \multicolumn{3}{|l|}{ Penyusutan } \\
\hline $\begin{array}{ll}\text { a. } & \text { X1 (untuk 1 kali } \\
\text { musim tanam) }\end{array}$ & 13282.07 & 22.34 \\
\hline $\begin{array}{l}\text { b. } \begin{array}{l}\text { X2 (untuk } 2 \text { kali } \\
\text { musim tanam) }\end{array}\end{array}$ & 10178.56 & 17.11 \\
\hline 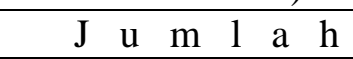 & 59460.63 & 100 \\
\hline
\end{tabular}

\section{Biaya Tenaga Kerja}

Tenaga kerja yang di gunakan dalam usahatani tomat berasal dari dua sumber yaitu

Tabel 7. Biaya Pengolahan Lahan, Penanaman, Pemeliharaan, Patok dan Pemetikan Hasil

\begin{tabular}{|c|c|}
\hline Komponen Biaya & Biaya $(\mathrm{Rp})$ \\
\hline \multicolumn{2}{|l|}{ Penyediaan dan Pengolahan Lahan } \\
\hline $\begin{array}{ll}\text { a. } & \text { X1 (untuk satu kali musim } \\
\text { tanam) }\end{array}$ & 650.000 \\
\hline $\begin{array}{l}\text { b. } \begin{array}{l}\text { X2 (untuk dua kali musim } \\
\text { tanam) }\end{array}\end{array}$ & 650.000 \\
\hline Penanaman & \\
\hline $\begin{array}{ll}\text { a. } & \text { X1 (untuk satu kali musim } \\
\text { tanam) }\end{array}$ & 875.000 \\
\hline $\begin{array}{l}\text { b. X2 (untuk dua kali musim } \\
\text { tanam) }\end{array}$ & 600.000 \\
\hline \multicolumn{2}{|l|}{ Pemeliharaan } \\
\hline $\begin{array}{ll}\text { a. } & \text { X1 (untuk satu kali musim } \\
\text { tanam) }\end{array}$ & 3.100 .000 \\
\hline $\begin{array}{l}\text { b. X2 (untuk dua kali musim } \\
\text { tanam) }\end{array}$ & 2.600 .000 \\
\hline \multicolumn{2}{|l|}{ Patok } \\
\hline $\begin{array}{l}\text { a. X1 (untuk satu kali musim } \\
\text { tanam) }\end{array}$ & 8.610 .000 \\
\hline $\begin{array}{l}\text { b. X2 (untuk dua kali musim } \\
\text { tanam) }\end{array}$ & 750.000 \\
\hline \multicolumn{2}{|l|}{ Pemetikan Hasil } \\
\hline $\begin{array}{l}\text { a. } \begin{array}{l}\text { X1 (untuk satu kali musim } \\
\text { tanam) }\end{array} \\
\end{array}$ & 3.325 .000 \\
\hline $\begin{array}{ll}\text { b. } & \text { X2 (untuk dua ka li musim } \\
\text { tanam) }\end{array}$ & 2.500 .000 \\
\hline
\end{tabular}

Sumber : Diolah dari data primer 2010 tenaga keja dalam keluarga dan tenaga kerja luar keluarga. Tenaga kerja luar keluarga yang di gunakan di upah berdasarkan hari kerja (6 jam/hari), dan pada penelitian ini tenaga kerja yang di gunakan tenaga kerja laki-laki upah yang di bayarkan Rp. 50.000 / hari orang kerja.

Untuk rata-rata penggunaan tenaga kerja dalam keluarga dan luar keluarga dapat di lihat pada Tabel 8. Dari Tabel 8, dapat di lihat bahwa rata-rata biaya tertinggi adalah biaya yang di keluarkan untuk tenaga kerja luar keluarga Rp. 438.888.89 untuk 1 kali musim tanam dan untuk biaya tertinggi ke 2 adalah tenaga kerja dalam keluarga Rp. 350.000 untuk 1 kali musim tanam.

Tabel 8. Biaya Rata-Rata Tenaga Kerja Dalam Keluarga dan Luar Keluarga

\begin{tabular}{|c|c|c|}
\hline Komponen Biaya & $\begin{array}{l}\text { Rata-Rata } \\
\text { (Rp) }\end{array}$ & $\begin{array}{l}\text { Persen } \\
\text {-tase }\end{array}$ \\
\hline \multicolumn{3}{|l|}{$\begin{array}{l}\text { Tenaga Kerja Dalam } \\
\text { Keluarga }\end{array}$} \\
\hline $\begin{array}{ll}\text { a. } & \begin{array}{l}\text { X1 (untuk 1 kali } \\
\text { musim tanam) }\end{array} \\
\end{array}$ & 402.777 .78 & 21.01 \\
\hline $\begin{array}{l}\text { b. } \begin{array}{l}\text { X2 (untuk 2 kali } \\
\text { musim tanam) }\end{array} \\
\end{array}$ & 300.000 & 15.66 \\
\hline \multicolumn{3}{|l|}{$\begin{array}{l}\text { Tenaga Kerja Luar } \\
\text { Keluarga }\end{array}$} \\
\hline $\begin{array}{ll}\text { a. } & \text { X1 (untuk 1 kali } \\
\text { musim tanam) }\end{array}$ & 480.555 .55 & 25.07 \\
\hline $\begin{array}{l}\text { b. } \begin{array}{l}\text { X2 (untuk } 2 \text { kali } \\
\text { musim tanam) }\end{array} \\
\end{array}$ & 733.333 .33 & 38.26 \\
\hline $\mathrm{J} \mathrm{u} \mathrm{m} \mathrm{la} \mathrm{h}$ & 1.916 .666 .66 & 100 \\
\hline
\end{tabular}

Sumber : Diolah dari data primer 2010

\section{Sarana Produksi}

Biaya untuk pembelian sarana produksi, yaitu biaya untuk pembelian bibit tomat, yang paling sering di gunakan oleh petani di Desa Tonsewer adalah bibit dengan jenis permata (Tomat apel), dan penggunaan pupuk Urea, Pupuk Ponska, Pupuk Tsp, serta Pestisida. Pestisida di gunakan apabila serangan hama penyakit atau di sesuaikan dengan kebutuhan tomat. 
Tabel 9. Biaya Sarana Produksi

\begin{tabular}{|c|l|}
\hline $\begin{array}{c}\text { Harga Sarana } \\
\text { Produksi }\end{array}$ & \multicolumn{1}{|c|}{ Harga } \\
\hline Benih & $\begin{array}{l}\text { Rp. 55000/ } \\
\text { bungkus }\end{array}$ \\
\hline Pestisida & Rp. 90.000/ Kg \\
\hline Antrakol & Rp. 75.000/ botol \\
\hline Amstar & Rp. 75.000/ botol \\
\hline Revus & Rp. 15.000/ botol \\
\hline Desis & Rp.16.000/ bungkus \\
\hline Detain & Rp. 85.000/ Kg \\
\hline Pupuk & Rp. 60.000/ Kg \\
\hline TSP & Rp. $90.000 / \mathrm{Kg}$ \\
\hline Urea & Rp. 60.000/ Kg \\
\hline Ponska &
\end{tabular}

\section{Harga}

Tingkat harga usahatani ini mengalami fluktuasi, hal ini di sebabkan oleh karena di pasar harga berubah-ubah. Berdasarkan penelitian yang di lakukan di Desa Tonsewer Kecamatan Tompaso, bahwa petani yang ada di desa tersebut sering memasarkan hasil produksi ke empat pasar yang berbeda, yaitu pasar Amurang, pasar Kawangkoan, pasar Tomohon dan pasar Manado. Sama hal dengan produksi harga juga berbeda tiap panenya. Dari hasil penelitian harga jual ratarata yang berlaku di tingkat petani adalah $\mathrm{Rp}$. 1.000 - Rp. 5.000 / Kg.

\section{Produksi}

Produksi merupakan hasil yang di peroleh petani pada saat panen. Penanaman Tomat dalam setahun di lakukan dalam 3 kali musim tanam . Dari hasil penelitian yang di peroleh data produksi Tomat petani di Desa Tonsewer bervariasi dari 680 kilogram sampai 9.100 kilogram/Ha. Besar kecilnya hasil produksi tidak hanya di tentukan oleh luas lahan, tetapi oleh faktor-faktor lain yaitu pemeliharaan tanaman, faktor tanah dan iklim dan yang paling penting adalah faktor hama dan penyakit tanaman.
Tabel 10. Persentase dan Produksi Tomat Petani di Desa Tonsewer

\begin{tabular}{|l|c|c|}
\hline Produksi (Kg) & $\begin{array}{c}\text { Jumlah } \\
\text { Petani } \\
\text { (orang) }\end{array}$ & $\begin{array}{c}\text { Persentase } \\
(\%)\end{array}$ \\
\hline$\leq .3000$ & 5 & 33.33 \\
\hline $3.001-6.000$ & 8 & 53.34 \\
\hline$\geq 6001$ & 2 & 13.33 \\
\hline Total & 15 & 100 \\
\hline
\end{tabular}

Sumber : Diolah dari data primer 2010

Berdasarkan Tabel 9, produksi Tomat di Desa Tonsewer Kecamatan Tompaso di bawah 3.001-6.000 kilogram yaitu sebesar 53.34 persen dari 15 responden. Pada umumnya produksi Tomat yang di hasilkan sesuai dengan luas lahan yang rata-rata kecil.

\section{Pendapatan dan Penerimaan}

Pendapatan adalah selisi antara penerimaan dan semua biaya yang di keluarkan suatu usahatani. Sedangkan penerimaan adalah perkalian antara jumlah produksi dengan harga jual yang berlaku di tingkat petani.

Tinggi rendahnya pendapatan petani akan tergantung pada produksi, harga jual dan biaya produksi yang di keluarkan selama proses produksi.

Tabel 11. Distribusi Pendapatan Menurut Pendapatan Petani

\begin{tabular}{|c|c|c|}
\hline $\begin{array}{c}\text { Pendapatan } \\
(\mathrm{Rp})\end{array}$ & $\begin{array}{c}\text { Jumlah } \\
\text { Responden } \\
(\text { Org })\end{array}$ & $\begin{array}{c}\text { Persen- } \\
\text { tase } \\
(\%)\end{array}$ \\
\hline $0-1.000 .000$ & 2 & 13.33 \\
\hline $110.00-2.000 .000$ & 1 & 6.68 \\
\hline $210.000-3.000 .000$ & - & - \\
\hline $310.000-4.000 .000$ & 5 & 33.33 \\
\hline $410.000-5.000 .000$ & 3 & 20 \\
\hline $510.000-6.000 .000$ & 2 & 13.33 \\
\hline$\geq 6.100 .000$ & 2 & 13.33 \\
\hline Total & 15 & 100 \\
\hline
\end{tabular}

Sumber : Diolah dari data primer 2010

Tabel 10 menunjukan bahwa pendapatan yang di peroleh dari usahatani tomat di Desa Tonsewer bervariasi. Pendapatan petani tertinggi adalah Rp. 12.193.774 per satu kali musim tanam 
dalam setahun. Rata-rata penerimaan tomat adalah Rp 8.121.111.11 untuk satu kali musim tanam dan Rp 7.728.333.33 per hektar dua kali musim tanam.

\section{Rasio Penerimaan dengan Biaya}

Analisis Revenue Cost di gunakan dengan tujuan untuk mengetahui tingkat keberhasilan petani dalam hal ini usahatani tomat apel dengan syarat apabila $\mathrm{R} / \mathrm{C}>1$ maka usahatani berhasil (untung), $\mathrm{R} / \mathrm{C}=1$ maka usahatani tidak untung atau tidak Rugi (seimbang), dan $\mathrm{R} / \mathrm{C}<1$ maka usahatani tersebut gagal (rugi). Tingkat keberhasilan tomat di Desa Tonsewer Kecamatan Tompaso yaitu, untuk R/C > 1 berjumlah 15 orang. R/C tertinggi yang diperoleh adalah sebesar 5.8 yang berarti setiap $\mathrm{Rp} 1,00$ biaya produksi yang di gunakan dalam usahatani tomat akan menghasilkan sebesar 6.2 sehingga dapat di katakana bahwa usahatani tomat memberikan keuntungan bagi petani.

\section{KESIMPULAN DAN SARAN}

Berdasarkan hasil penelitian dan pembahasan analisis pendapatan usahatani tomat di Desa Tonsewer Kecamatan Tompaso, maka diketahui untuk pendapatan usahatani tomat tertinggi adalah Rp12.193.774 per satu kali musim tanam dalam satu tahun dan untuk pendapatan tertinggi dua kali musim tanam adalah Rp 5.627.194, untuk pendapatan usahatani terendah Rp 380.746 per satu kali musim tanam dalam satu tahun dan Rp 753.250 per dua kali musim tanam. Rata-rata pendapatan yang diperoleh petani per satu kali musim tanam dalam satu tahun adalah $\mathrm{Rp} 5.047 .673$ dan rata-rata pendapatan yang diperoleh petani per dua kali musim tanam dalam satu tahun adalah $\mathrm{Rp}$ 3.386.987.8. Untuk rata-rata besar biaya produksi yang di keluarkan $\mathrm{Rp}$ 4.341.345.25 per dua kali musim tanam dan Rp. 3.073.504.29 biaya produksi yang di keluarkan per satu kali musim tanam.

\section{Saran}

Untuk memperoleh harga jual yang tinggi, disarankan agar petani mengatur waktu penanaman agar tidak dilakukan secara serempak.
Cara ini dilakukan untuk menghindari produksi yang melimpah yang mengakibatkan harga tomat akan jatuh.

Disarankan pula agar petani tomat menjual produknya ke swalayan atau melihat prospek keluar, tidak hanya menjual pada pasar lokal. Agar petani dapat lebih banyak memperoleh keuntungan, dalam uasahatani tomat yang mereka kerjakan.

\section{DAFTAR PUSTAKA}

Anonimous, 2010. Fungsi Produksi. http://www.e-dukasi.net. Diakses 2 Februari 2010 Pukul 12:00.

Anonimous, 2010.2 Produksi. http://id.wikipedia.org.Diakses 2 Februari 2010 Pukul 12:00.

Anonimous, 2010. Definisi Usahatani. http://ac.id/files pertemuan -1.Ppt+definisi Usahatani.id. Diakses 2 Februari 2010 pukul 14:00.

Anonimous, 2010. Pengembangan Produksi Hortikultura. http://geothermal.itb.ac.id. Diakses 3 Februari 2010 pukul 16:00.

Anonimous, 2010. Pembudidayaan Tomat Secara Komersil. http://www.belbuk.com/tomat pembudidayaan-secara-komersial-p9856.html. Diakses 3 Februari 2010 Pukul 16:00.

Hendri Gerungan, 1999. Analisis Pendapatan Usahatani Caberawit, di Kec.Tomohon. Kab. Minahasa. Seminar Usulan Penelitian Fakultas Pertanian, UNSRAT Manado.

Hermanto, F, 1993. Ilmu Usahatani. Departemen Sosil Ekonomi. Bandung.

J. D. Makeham dan R. L. Malclom. 1991. Manajemen Usahatani Daerah Tropis. LP3ES. Jakarta.

Kandariah, 1994. Teori Ekonomi Mikro. Fakultas Ekonomi Universitas Indonesia. Jakarta.

Meilanny Grace Ticoalu, 2003 Analisis Biaya dan Pendapatan Usahatani Tanaman Tomat Dan Padi Di Areal Persawahan. Seminar Usulan Penelitian Fakultas Pertanian, UNSRAT Manado. 
Patricia Mega Sigar, 2001. Analisis Pendapatan Usahatani Tomat Apel di Desa Kunyangan Kecamatan Tombatu. Skripsi Fakultas Pertanian Usrat Manado.

Ronny. M. Sondakh, 2010. Pendapatan Usahatani Campuran Di Desa Kumu Kec. Tombariri. Seminar Hasil Penelitian Fakultas Pertanian, UNSRAT Manado.

Rofemton, F, 2003. Analisa Pendapatan Usahatani Tomat Studikasus Di Desa Toure dan Tounsewer Di Kecamatan Tompaso. Skripsi Fakultas Pertanian, UNSRAT Manado.

Soekartawi, 1995. Analisis Usahatani. Universitas Indonesia. Jakarta.

Soekartawi, Soeharjo, Dillon dan Hardaker, 1986. Ilmu Usahatani dan Penelitian Untuk Pengembangan Petani Kecil. Universitas Indonesia. Jakarta 